\title{
CORÉIA AGUDA NA GRAVIDEZ
}

\author{
WAlter C. Pereira* \\ Domingos Delascio **
}

A ocorrência de coréia aguda durante a gravidez é rara. Há, contudo, grande variabilidade de dados quanto à freqüência desta afecção na experiência dos diferentes autores. Willson e Preece ${ }^{21}$ encontraram um caso de coréia aguda em cada 2.275 gestações. Beresford e Graham ${ }^{2}$ referem a proporção de $1 / 2.830$ e Eastman e Hellman ${ }^{8}$, de $1 / 50.000$. Briquet ${ }^{3}$ Rudge e Silveira ${ }^{17}$, em nosso meio, registram a incidência de um caso de coréia aguda em cada 1.000 e 12.620 pacientes grávidas, respectivamente.

A raridade com que esta afecção é encontrada durante a gestação, assim como a controversia existente a respeito de seus aspectos fisiopatogênico, prognóstico e terapêutico, motivaram a realização dêste trabalho, no qual apresentamos casuística reunida durante os últimos onze anos.

\section{CASUISTICA}

De maio de 1956 a junho de 1967 foram observados 12 casos de coréia aguda ocorridos em 9 gestantes internadas na Casa Maternal e da Infância «Leonor Mendes de Barros» (quadro 1). Durante o mesmo periodo de tempo foram atendidas cêrca de 150.000 parturientes. A relação entre gestantes corêicas e normais foi, portanto, de 1/12.500. A idade das pacientes variou de 18 a 34 anos, estando a média em tôrno dos 22,3 anos. Quanto à côr, seis pacientes eram brancas, duas pardas e uma negra. Quanto ao estado civil, duas eram solteiras, sendo as demais casadas. Três doentes foram reinternadas com recidiva do surto corêico (casos 1-2, 4-5, 10-11). Em cinco casos a coréia ocorreu na primeira gestaçāo (casos 1. 4, 7, 8, 12); em quatro, na segunda (casos 5, 6, 9, 10); em dois, na terceira (casos 3 e 11) e, em um, na quinta (caso 2).

Quanto aos antecedentes mórbidos, havia referência a surtos anteriores de coréia em sete pacientes: quatro tinham apresentado coréia gravidica pregressa ( $\operatorname{cosos} 2,3,5,11)$; duas, coréia infantil (casos 8e 9) e, uma, ambas as formas (caso 6). Manifestaçōes articulares inflamatórias foram relatadas por duas pacientes (casos 1-2,7). Sinais suspeitos de cardiopatia crônica, com lesōes orovalvulares, foram encontrados em três doentes (casos 7, 8, 10-11).

$O$ início da sintomatologia ocorreu no primeiro trimestre da gravidez quatro vêzes (casos 3, 6, 9, 12); no segundo, seis ( $\operatorname{casos} 2,4,5,7,10,11)$; no terceiro, duas (casos 1 e 8). A duraçāo média do surto foi de aproximadamente três meses. Nos casos em que os sintomas persistiram até o fim da prenhez ocorreu total remissāo dos mesmos nos primeiros dias do puerpério (casos $1,2,3,4,5$, 7 , 8). Em onze casos a hipercinesia era difusa e bastante intensa; no caso 3

Trabalho da Casa Maternal e da Infância «Leonor Mendes de Barros»: * Neurologista; ** Diretor-clinico. 


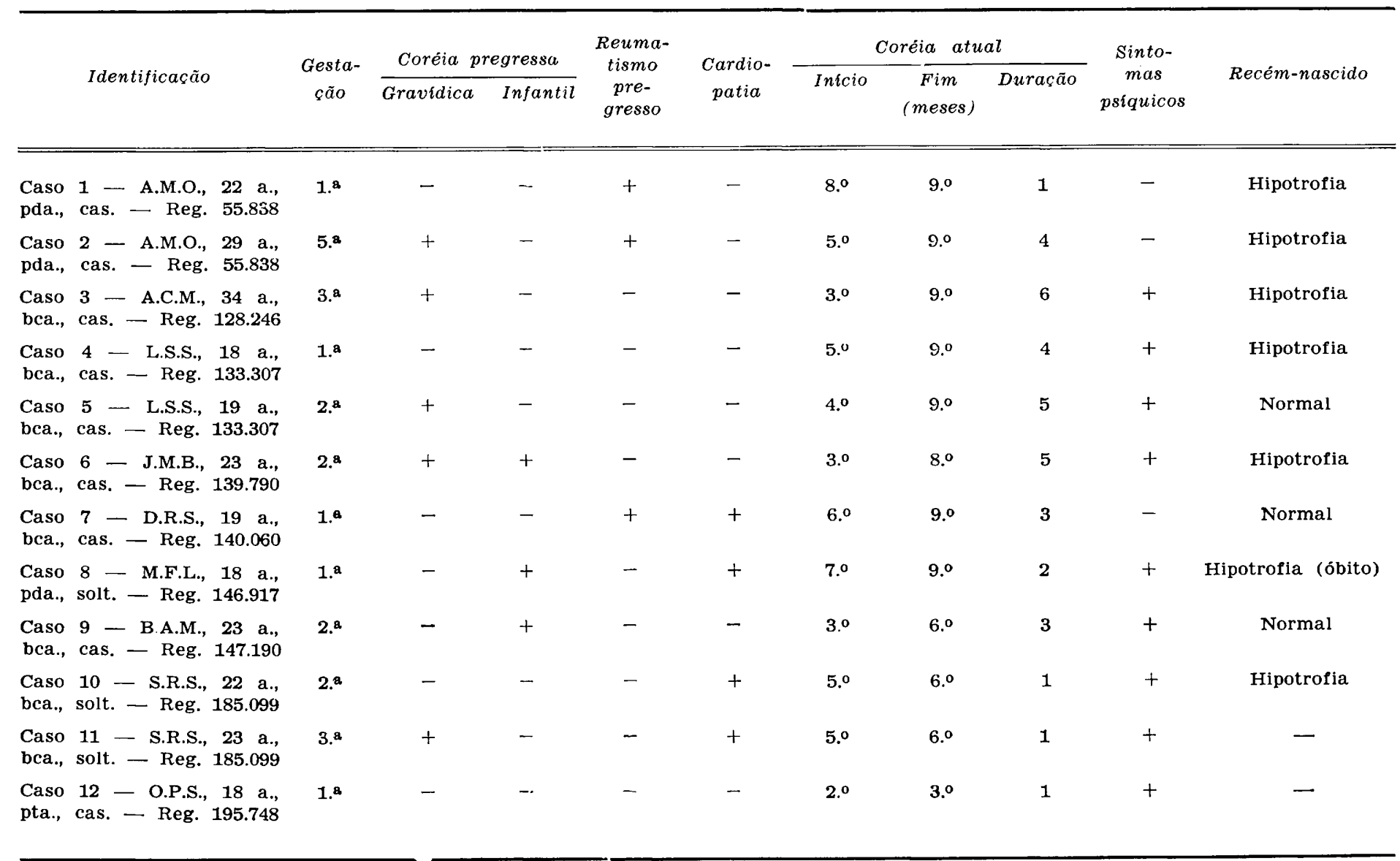

Quadro 1 - Dados relativos a 12 casos de coréia aguda observados em 9 gestantes. Abreviaturas: bca., branca; cas., casada; solt., solteira; pda., parda; pta., preta; Reg., registro. 
os movimentos parasitas predominavam nitidamente no dimidio esquerdo (hemicoréia). Em nenhuma doente ocorreu hipertermia, assim como não foram encontrados outros sinais de processo infeccioso em atividade, durante todo o periodo em que ficaram sob observação. Sintomas psíquicos, tais como extrema labilidade emocional e tendência à depressão, angústia e irritabilidade eram evidentes cm sete das nove pacientes, persistindo durante tôda a evolução do quadro.

Foram feitos hemogramas em quatro casos, revelando anemia hipocrômica, leucocitose e neutrofilia discretas. A hemossedimentação, feita em dez casos, mostrou-se acelerada em 9 e normal em um. As mucoproteinas foram dosadas em três doentes, tendo apresentado valores normais. A proteina $C$ reativa foi pesquisada em 9 casos, não mostrando em caso algum valor significativo como reagente da fase aguda do sôro. A reação de Weltman foi feita em três casos com zona de coagulação até o $80^{\circ}$ tubo.

Todos os casos foram tratados com sedativos (fenotiazínicos e barbitúricos) e colocados em condições de repouso absoluto em quarto obscurecido. $O$ ácido acetilsalicilico foi também administrado a tôdas as pacientes, na dose de $4 \mathrm{~g}$ diárias. A penicilina benzatina foi empregada nos casos 5, 8, 9, 10, 11; corticosteróides foram administrados nos casos 2 e 5 .

Em dez casos ocorreu parto espontâneo e normal nas proximidades do termo. Duas pacientes (casos 11 e 12) não chegaram ainda ao termo da gestação, estando, contudo, assintomáticas em relação ao quadro corêico. Todos os recémnascidos apresentaram vitalidade satisfatória, sendo três normais quanto ao pêso e sete ligeiramente hipotróficos. Houve apenas um caso de óbito neonatal determinado por choque hemorrágico (rotura da veia subclávia causada por fratura da clavicula durante as manobras de parto).

\section{COMENTARIOS}

Briquet ${ }^{3}$, em 1953, refere em nosso meio a incidência de um caso de coréia aguda em cada 1.000 pacientes obstétricas. Rudge e Silveira ${ }^{17}$, em 1951, estudaram três pacientes corêicas encontradas entre 37.561 parturientes internadas na Casa Maternal e da Infância "Leonor Mendes de Barros no período de 1944 a 1951. Estes autores consideram a relação de 1.12.520 como sendo a incidência real da coréia entre pacientes gestantes no Município de São Paulo; a incidência que encontramos entre 150.000 partos realizados no mesmo Serviço, desde maio de 1956 até junho de 1967, foi de $1 / 12.500$, confirmando, portanto, essa afirmativa.

Willson e Prece ${ }^{21}$ baseando-se em 666 observações, nas quais a idade das doentes era mencionada, encontraram a idade média de 22,4 anos para a coréia gravídica, que é pràticamente igual à encontrada em nosso material (22,3 anos). Quanto à côr, considera-se a raça negra como excepcionalmente atingida pela coréia; Rabin e Duék ${ }^{15}$ referem que até 1942 havia sòmente um caso de gestante corêica da raça negra registrado na literatura mundial. Entre nossas nove gestantes com coréia aguda três eram da raça negra. Quanto ao estado civil, havia duas solteiras entre nossas pacientes (22\%); segundo as opiniōes de Beresford e Grahan ${ }^{2}$ e de Willson e Preece ${ }^{21}$, contrariando a afirmativa de outros autores, a ilegitimidade da união entre os conjuges não parece ser fator importante no desencadeamento da coréia grávídica.

A ocorrência da maioria dos casos de coréia durante a primeira gestação, assim como seu decréscimo progressivo nas prenhezes ulteriores, é fato assinalado por todos os autores. Entre nossas pacientes registramos $41 \%$ dos 
casos na primeira gravidez, $33 \%$ na segunda, $18 \%$ na terceira e $8 \%$ na quinta. A recidiva do surto em prenhezes sucessivas, também relatada freqüentemente, foi observada em cinco de nossas pacientes. Fato digno de menção ocorreu com a paciente A. M. O. que apresentou surto corêico na primeira gestação sòmente vindo a repetí-lo na quinta prenhez, sete anos depois (casos 1 e 2). Em três doentes havia referência à coréia aguda na infância. No total das pacientes estudadas havia sete com antecedentes de coréia na infância e/ou em prenhez anterior $(77,8 \%)$. Tal percentagem é superior à mencionada por Willson e Preece ${ }^{21}$ que encontraram precedentes corêicos em 60,9\% das pacientes com coréia gravíca. A questão inversa, ou seja, a freqüência com que doentes que tiveram coréia na infncia ou adolescência apresentam nôvo surto durante a gravidez é de $4 \%$ aproximadamente ${ }^{21}$.

Manifestações articulares inflamatórias foram referidas por duas de nossas doentes (22\%). Beresford e Graham ${ }^{2}$ encontraram as mesmas queixas em 26,9\% de seus casos, enquanto que Willson e Preece 21 referem-nas em $39,7 \%$. Lesões cardíacas orovalvulares foram suspeitadas em três de nossas doentes $(33 \%)$. Willson e Preece ${ }^{21}$ assinalaram cardiopatia comprovada ou provável em $48,8 \%$ das pacientes com coréia gravídica. Beresford e Graham ${ }^{2}$ fizeram o mesmo diagnóstico em $34,6 \%$ de seus casos. Rudge e Silveira ${ }^{11}$ encontraram a elevada incidência de 68,75\% de cardiopatia entre os 20 casos de coréia gravídica publicados até 1951 na literatura brasileira.

Em nossa casuística a sintomatologia se iniciou no primeiro trimestre da prenhez em 33\% dos casos, no segundo em 50\% e, no último, nos restantes $17 \%$. Beresford e Graham ${ }^{2}$ também encontraram a maioria dos casos de coréia incidindo durante o segundo trimentre da gravidez $(50 \%)$. Willson e Preece ${ }^{21}$, no entanto, estudando 951 gestantes corêicas, relatam o início da sintomatologia em $50 \%$ dos casos no primeiro trimestre, decrescendo para $33 \%$ e $17 \%$ no segundo e terceiro trimestres, respectivamente. A duração média do surto em nossas doentes foi de três meses. É preciso notar, porém, que a maioria dos casos tratados logo no início do quadro tiveram remissão da sintomalogia mais precocemente $(\operatorname{casos} 1,8,10,11,12)$. As demais pacientes procuraram o Serviço já com vários meses de doença, geralmente nas proximidades do termo da gestação, sòmente então sendo iniciado o tratamento. Lewis e Parsons ${ }^{11}$ referem que a duração média do surto de coréia gravídica está ao redor de quatro meses. Observamos, como refere a maioria dos autores, que após o parto há tendência ao rápido desaparecimento do quadro hipercinético e dos sintomas psíquicos. Em nenhuma de nossas doentes a coréia se cronificou como é referido em alguns casos citados na literatura 17, 21. Mesmo nas pacientes que tiveram recidiva do surto corêico em prenhez ulterior os sintomas mantiveram-se ausentes no intervalo entre as gestações. Não houve caso algum de óbito entre nossas doentes, embora trabalhos recentes ainda refiram mortalidade de 20 a $25 \%$ na coréia aguda da gravidez $1,11$.

A etiologia da coréia tem sido muito controvertida. Numerosas hipóteses fisiopatogênicas foram aventadas dando origem a diversas teorias: 
constitucional, endócrina, alérgica, nutricional, psiconeurótica, tóxica e infecciosa $1,12,7,10,11,12,13,15,17,18,20,21$.

Baker ${ }^{1}$ classifica as coréias em infecciosas, vasculares e degenerativas; a coréia aguda (ou de Sydenham) seria determinada pricipalmente por agentes infecciosos ou fatôres vasculares e a coréia crônica (ou de Huntington) por lesões degenerativas. Considera ainda a coréia aguda como uma síndrome desencadeada por numerosos agentes, tais como estreptococos hemolíticos, vírus filtráveis, metabólitos anormais, alergenos e substâncias tóxicas com afinidade especial para os núcleos da base do encéfalo. Como antecedentes de febre reumática são encontrados de 20 a $80 \%$ dos pacientes com coréia aguda ela foi apontada como a causa principal desta afecção 3, 1.2, 17, 21. Trabalhos recentes, no entanto, preferem considerar a febre reumática não como a causa da coréia, mas meramente participando do mesmo complexo sintomático do qual fazem parte surtos freqüentes de faringo-amigdalites, cardiopatia, manifestações inflamatórias articulares e coréia 1,5 .

Do ponto de vista anatomopatológico não se encontram na coréia aguda os nódulos de Aschoff característicos das manifestações articulares e cardiacas da febre reumática. Os cortisosteróides, empregados com êxito no tratamento do processo inflamatório agudo e na prevenção de fibrose na febre reumática, não costumam surtir igual efeito quando utilizados na coréia. Sob êste aspecto é interessante lembrar que durante a gravidez, quando o teor de corticosteróides é mais elevado, as manifestaçōes cardiacas e articulares da febre reumática costumam involuir, ao contrário do que sucede com a coréia. Os reagentes da fase aguda do sôro (hemossedimentação, mucoproteinas, proteina $\mathrm{C}$ reativa, reação de Weltman) e a eletroforese das proteínas séricas são em geral normais na coréia aguda, enquanto que se mostram bastante alterados na febre reumática em atividade ${ }^{4,19}$. Todos os fatos acima citados sugerem a existência de diferenças fisiopatogênicas entre a coréia e a febre reumática.

Atualmente acredita-se que a coréia seja determinada, na maior parte dos casos, por uma alergo-sensibilização provocada por toxinas bacterianas. Entre estas o estreptococo beta hemolítico do grupo $A$ de Lancefield é o que mais freqüentemente determina êsse estado de sensibilização dos núcleos da base do encéfalo, embora outras bactérias, como o pneumococo, também produzam estreptolisinas. A alergo-sensibilização relaciona-se mais com os antígenos $M$ da cápsula do estreptococo. Como apenas alguns poucos indivíduos com infecções estreptocócicas freqüentes apresentam febre reumática, cardiopatia ou coréia, admite-se também que seja necessário existir predisposição constitucional para que se instale a alergo-sensibilização.

Em nosso material a fisiopatogenia da coréia não ficou suficientemente esclarecida em caso algum. Nenhuma paciente apresentou hipertermia ou outros sintomas que pudessem sugerir processo infeccioso agudo em atividade. O hemograma revelcu, nos quatro casos em que foi feito, anemia hipocrômica, leucocitose e neutrofilia discretas que durante a prenhez não podem ser valorizadas. A hemossedimentação mostrou-se acelerada em nove dos dez casos em que foi feita; êste dado também é desprovido de valor pois 
durante a gravidez a velocidade da hemossedimentação está normalmente aumentada. As mucoproteinas e a proteina $C$ reativa apresentaram valores normais em todos os casos em que foram dosadas. A reação de Weltman, feita em três casos, apresentou zona de coagulação à direita, enquanto que na fase aguda do sôro esta se encontra à esquerda. Os exames complementares, portanto, confirmando o que geralmente é relatado na coréia pura, não mostram as alterações características da fase aguda do sôro que, pelo contrário, são encontradas na maioria dos pacientes com febre reumática em atividade. $O$ exame de laboratório que mais freqüentemente fornece subsídio de valor no sentido do diagnóstico etiológico da corẻia é a dosagem da antistreptolisina $O$. Este anticorpo é encontrado em niveis significativamente elevados em cêrca de $50 \%$ dos casos de coréia infantil, denunciando infecções estreptocócicas recentes ${ }^{6}$. Em nenhuma de nossas pacientes foi possivel realizar êste exame.

Os sintomas psíquicos, encontrados em sete das nove doentes, nos pareceram ser mais o efeito do que a causa da coréia, pois a presença da hipercinesia incoercivel provoca depressão e angústia intensas. Em 77,8\% de nossos casos havia referência a surtos pregressos de coréia. É possível que a gravidez atue, pelo menos em alguns casos, exacerbando lesões cicatriciais quiescentes e, mesmo na ausência de processo inflamatório ativo, possa desencadear a hipercinesia. A prenhez pode constituir-se em fator inespecífico de hipersensibilização, reagudizando dessa maneira lesōes assintomáticas dos núcleos basais. Os fatôres vigentes na gestação responsáveis por êste fenômeno são desconhecidos. A recidiva da coréia durante a gravidez em doentes que tiveram surtos na infância é, no entanto, pouco freqüente ${ }^{21}$.

O tratamento que adotamos visou principalmente a sedação das pacientes o que reduz acentuadamente a hipercinesia, fazendo-a desaparecer completamente com o sono. Os medicamentos empregados com essa finalidade foram fenotiazínicos e barbitúricos em doses variáveis de acôrdo com a necessidade 9,22 . O ácido acetilsalicílico foi também administrado a tôdas as pacientes na dose média de $4 \mathrm{~g}$ diárias.A penicilina benzatina foi empregada em cinco casos na suposição de haver infecção estreptocócica, embora faltassem elementos para tal diagnóstico. Os corticosteróides foram usados em apenas dois casos que se apresentavam rebeldes ao tratamento até então instituído não se observando, porém, resultados favoráveis com os mesmos.

Nos dez casos em que as pacientes chegaram ao termo da gestação o parto ocorreu espontânea e normalmente. Em nenhum caso foi necessária a indução prematura do parto, como aconselham alguns autores, com a finalidade de interromper surtos corêicos mais graves 1, 2, 3, 12, 16, Julgamos mesmo que tal conduta nunca se imponha realmente, pois a sedação e o repouso costumam melhorar acentuadamente a hipercinesia e os sintomas psíquicos. Em relação aos recém-nascidos, todos apresentaram vitalidade satisfatória, ocorrendo apenas um caso de óbito conseqüente a choque hemorrágico. Beresford e Graham ${ }^{2}$ referem a mortalidade fetal de 3,3\% em gestações corêicas. Esta mortalidade aumenta consideràvelmente quando o parto é induzido prematuramente, podendo nestes casos atingir, segundo 
Wilson e Preece ${ }^{21}$ a enorme incidência de $50,9 \%$. Duas de nossas pacientes ainda não atingiram o termo da gestação, estando, porém, assintomáticas quanto ao quadro corêico.

\section{RESUMO}

São apresentados doze casos de coréia aguda observados entre 150.000 gestantes(1/12.500). A maioria dos surtos ocorreu no segundo trimestre da primeira gravidez. A duração média dos sintomas foi de três meses, não tendo sido registrado caso algum de óbito materno. Todos os partos foram espontâneos e normais. Houve apenas um óbito fetal conseqüente a choque hemorrágico. São tecidas considerações a propósito dos aspectos clinico, laboratorial e prognóstico da coréia gravídica, sendo focalizado mais pormenorizadamente o problema fisiopatogênico dessa afecção.

\section{SUMMARY}

Acute chorea in pregnancy: comments on twelve consecutive cases.

Twelve consecutive cases of acute chorea occurring among 150.000 pregnant women (1/12.500) are reported. Most of the cases occurred from the fourth do the sixth month of the first pregnancy. The average duration of the symptoms was of three months and no one case of maternal death was verified in the group. The deliveries were spontaneous and normal in all the patients. Only one case of fetal death occurred in consequence of a hemorragic shock. Comments are made on the clinical, laboratorial and prognostic features of chorea gravidarum, being particulary focused the physiopathogenic problem of this condtion.

\section{REFERENCIAS}

1. BAKER, A. B. Clinical Neurology, ed. 2. Hoeber, New York, 1962.

2. BERESFORD, O. D. \& GRAHAM, A. N. - Chorea gravidarum. J. Obstet. Gynaec. Brit. Emp. 57:616-625, 1950.

3. BRIQUET, R. - Sôbre um caso de coréia gravídica tratada com injeções intrarraquidias de electrargol. Rev. Obstet. Ginec. São Paulo 1:1-9, 1935.

4. CALZOLARI, C. \& BORGHERESI, S. - Osservazioni sui rapporti fra infezioni streptococeica, corea minor e malattia reumatica. Riv. Clin. pediat. 68:133-149, 1961.

5. DIAmENT, A. J. - Coréias agudas. In Canelas, H. M. - Manual de Clínica Neurológica, Sarvier, Editora da Universidade de São Paulo, 1967.

6. DIAMENT, A. J. - Comunicação pessoal, 1967.

7. DUTRA, L. H. - Coréia gravídica. Tratamento pela vitamina $B_{6}$. Rev. paul. Med. 22:307-309, 1943 
8. EASTMAN, N. J. \& HELLMAN, L. M. - Williams Obstetrics. 3.a edição. Appleton, New York, 1966

9. ELLIS, A. H. \& ILL, E. - Chorea gravidarum. Amer. J. Obstet. Gynec. $72: 1343-1345,1956$.

10. GOSENDE, J. C. \& SANDiAno, R. O. - Corea y embarazo. Bol. Soc. Obstet. Ginec. Buenos Aires 23:798-810, 1944.

11. LEWIS, V. B. \& PARSONS, M. - Chorea gravidarum. Lancet i:284-286, $196 t$.

12. MC ELIN, T. W.; LOVELADY, S. B.; WOLTMAN, H. W. \& MINN, R. Chorea gravidarum. Review of the recent literature and report of five cases. Amer. J. Obstet. Gynec. 55:992-1006, 1948.

13. MELLO, G. - Chorea gravidica. Rev. Ginec. Obstet. (Rio de Janeiro) 17: $124-131,1923$.

14. MULLA, N. - Chorea gravidarum. Obstet. and Gynec. 2:79-81, 1958.

15. RABIN, S. \& DUEK, H. - Coréia gravídica. Observação de um caso curado pela vitamina $B_{6}$. An. bras. Ginec. 14:12-21, 1942.

16. RUVINSKY, J. J. \& GUTTMACHER, A. F. - Medical, Surgical and Gynecologic Complications of Pregnancy. Williams \& Wilkins, Baltimore, 1965.

17. RUDGE, W. S. \& SILVEIRA, J. M. - Coréia gravídica. A propósito de cinco casos. Matern. \& Inf. (São Paulo) 10:5-40, 1951.

18. SCHWARTZMAN, J.; DRAGUTSKY, D. \& ROOK, G. - Sydenham's chorea. Report of three cases successfully treated with vitamina $B_{6}$. J. Pediat, 19: $201-204,1941$.

19. SOREL, R.; DALOUS, A.; DEGOY, A. \& SALANOVA, J. - La place nosologique de la chorée subaiguë de Sydenham. Toulouse méd. 64:481-488, 1963.

20. WEIGNER, W. C. - Chorea gravidarum. A study of psychogenic factors therein, with a report of a case. Amer. J. Psychiat. 93:843-855, 1937.

21. WILLSON, P. \& PREECE, A. A. - Chorea gravidarum. A statistical study of 951 collected cases, 846 from the literature and 105 previously unreported. Arch. intern. Med. 49:471-553 e 671-697, 1932.

22. 'WINKELBAUER, R. G. \& KINSEY, L. R. - Chorea gravidarum treated with chlorpromazine. Amer. J. Obstet. Gynec. 71:1353-1354, 1956.

Casa Maternal e da Infância "Leonor Mendes de Barros" - Av. Celso Garcia 2477 - São Paulo, SP - Brasil. 